\author{
S. Cobb, J. R. P. French, Jr., R. L. Kahn, F. C. Mann \\ Intercenter Program on Mental Health in Industry, Institute for Social Research, \\ The University of Michigan, Ann Arbor, Mich.
}

Since the days of Freud, the major focus in the field of mental health has been on the individual and on his personality. It is now time to start moving toward a better balance in emphasis between host and environmental factors (W.H.O., 1960). In order to achieve this, some research groups that focus more on the environment than on the personality are needed. This is a natural approach for those of us in Public Health; for we know all too well that it is primarily in those areas where we have identified specific environmental factors that contribute to disease and where these factors have been amenable to mass change, that substantial prevention has been accomplished. Such things as the purification of water supplies by sand filtration and chlorination and the elimination of anopheline mosquitoes with DDT spraying come to mind. One wonders what would happen if we could, over the next couple of generations, make as much progress in the hygiene of interpersonal and social relations as was made in the first half of this century in the hygiene of the physical environment.

Lest we ramble, it is essential to define our terms and the basic problems at issue. This is difficult when the orientation is to the positive aspect of mental health, because the whole concept of positive health is elusive. Elsewhere (French and Kahn, 1962), we have laid out our views on this matter and enumerated a set of relevant concepts. These concepts vary greatly in their measurability. For example, self-esteem is now becoming measurable thanks to the development of the concepts of multiplicity of the dimensions of self-identity and the centrality of these dimensions (Sherwood, 1962). On the other hand, measurement techniques for such things as degree of integration of the personality, the level of interpersonal competence, or extent of adjustment are still in their infancy. It seems appropriate, then, to suggest that for the immediate future, most field studies should focus on the more measurable negative side which will, for convenience, be called the problem of mental health.

Our conceptualization of this problem of mental health is laid out in FIGURE 1. In this figure are found the major host and environmental factors contributing to "Dis-Ease," the various behaviors resulting from "DisEase," and finally the nature of the treatment elicited by the relevant behavior. The continuum, "Dis-Ease," has at one end, somatic illness, which is characterized by lesions visible with usual pathological techniques and is derived primarily from genetic defects, microbial invasion, exposure to toxic substances, etc. At the other end of the continuum is social maladjustment which is derived primarily from the interaction of personality with the social environment. The fact that they may each contribute to each other is emphasized by the two-headed arrow between them. Both 
Host

Factors

Environ-

mental

Factors

"Dis-Ease"

Behavior

Treatment
GENES

PERS ONAL ITY

SOCIAL ENV IRONMENT

SOC I A L

I L L NESS $\longleftrightarrow$ MALA D JUSTMENT

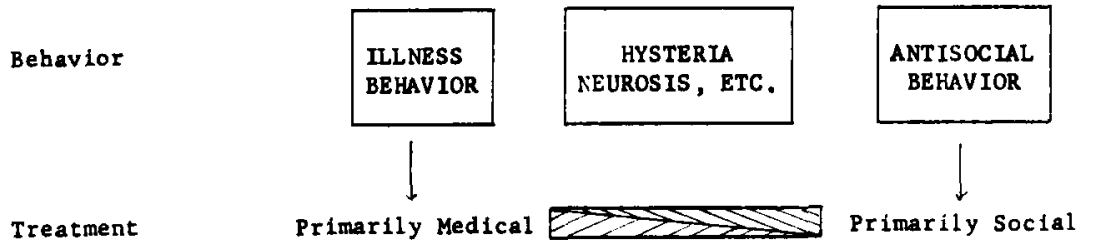

Figure 1. A conceptualization of the problem of mental health.

of them may contribute to illness behavior by which is meant taking up the sick role by complaining, neglecting usual duties, and seeking therapeutic help, as indicated by the arrows from each to illness behavior. In addition, social maladjustment contributes to the category: hysteria, neurosis, and the like; which represents that part of what is usually called mental illness for which no gross or microscopic lesions have been demonstrated and in which the principle manifestations are behavioral. This is the area that has been so interestingly handled by Szasz (1961) in his book, The Myth of Mental Illness. The schizophrenics would be included here by some and not by others; but general paresis, i.e., central nervous system syphilis, does not belong here and does belong under somatic illness. Finally, social maladjustment may lead to various forms of antisocial behavior. In the industrial setting, this may range all the way from refusing to join the union to physical assault and murder. Of course, somatic illness and altered physiological states can contribute to neurosis and to antisocial behavior. For simplicity, this diagram assumes that these effects are through social maladjustment resulting from the illness even though this may not always be the case. As examples of this not always being the case, we might cite the phenomenon of psychomotor epilepsy producing aggressive behavior (Forster, 1955) and the long known and now well-described phenomenon of altered behavior associated with menstruation (Dalton, 1960a, b, $c$; 1961 ).

The treatment implications of this diagram are of some interest. As a matter of fact, the germ of the idea that led to the development of this diagram arose from consideration of the difference between a hypochon- 
driac and a union agitator advocating a slow down. Both are suffering from social maladjustment and both are contributing to inefficiency in the plant; but the first is treated in the medical department and the second is handled by the labor relations department. What this paradigm seems to imply is that there is a continuous gradient from the mechanical manipulation of bones, as in orthopedic surgery, through the mixed operations of the general practitioner to the more environmentally oriented operations of the psychiatric social worker and to the extreme social phenomenon of the penologist. The psychiatrists sit somewhere in the middle of all this, and the most eclectic of them, who are perhaps the most effective, range the scale widely from one end to the other.

All the elements of this diagram are reasonably well defined in current usage except for the concept of social maladjustment. Since social maladjustment is a key piece, it is important that we define it clearly and specifically. Social maladjustment is taken to mean chronic dissatisfaction with self, with others, or of others with self. Many negative emotions are involved from anger, fear, and depression to the more complex affects of jealousy and loneliness.

It should be noted that acute temporary dissatisfactions are excluded from this definition as are dissatisfactions with things and with the state of affairs. Our attention, then, is focused on matters that are interpersonal and are of an enduring nature. Specifically, dissatisfaction with one's job is not necessarily evidence of social maladjustment if the source of this is the wage scale or the disagreeable nature of the work. However, if this dissatisfaction is with one's supervisor, with one's coworkers, or with one's own ability to do the job, it is evidence of some social maladjustment in the situation. Or taking it one step further, dissatisfaction with wages is not evidence of social maladjustment if one is satisfied that one's superiors are doing everything they can to rectify the situation. Unfortunately, data are not always obtained in sufficient detail to make these distinctions; and sometimes the information is not available at conscious levels, so we are often forced to draw inferences about the presence or absence of maladjustment. Despite this difficulty of getting right to the heart of the matter, this definition has operational characterisics for it permits us to identify social maladjustment by seeking for various types of chronic interpersonal dissatisfaction. The fact that all social maladjustment cannot be identified with ease is a matter for concern but not one which will prevent progress.

We are now in a position to make another operational definition; to wit, the problem of mental health, which is here recognized as encompassing the adverse effects of social maladjustment, is measured in terms of illness; in terms of illness behavior; in terms of hysteria, neurosis and the like; and finally, in terms of antisocial behavior. This is, of course, clearly a public health point of view for it implies that an individual can be thoroughly dissatisfied, unhappy, resentful, or what-have-you; but as long as this does not result in illness or in inappropriate behavior, it is not part of the problem of mental health. Similarly, those with neurotic tendencies do not become part 
of the problem of mental health unless the environment is such as to elicit inappropriate or disfunctional behavior (Alexander, 1962).

Having defined the problem of mental health, we can proceed at once to set two research tasks for those of us who are pursuing it in the industrial environment. The first of these tasks is to identify those groups which have high rates for social maladjustment. The second is to identify relationships between specific types of social maladjustment and the various illness and behavioral patterns with which we may be concerned. The remainder of this discussion will be devoted to the presentation of illustrative data from our own research that bears on these points. These illustrations will be organized around the several boxes in FIGURE 1. First, the distribution of social maladjustment will be discussed. Then, the relationship of social maladjustment to illness, to illness behavior, to hysteria, neurosis, etc., and to antisocial behavior will each be illustrated in turn.

Distribution of social maladjustment. TABLE 1 presents a list of suspected sources of social maladjustment along with our present conceptualizations of the principal psychological factors involved. The first three seem to be mostly related to chronically low or suddenly lowered self-esteem. Low status in the company hierarchy is popularly acknowledged to be a source of dissatisfaction in the upwardly striving American culture. General illness and mortality rates have regularly been found to be highest in the lower social classes (Committee for Special Research in H.I.P., 1957; Metropolitan Life Ins. Co., 1960; Registrar General, 1958). It has been presumed that a variety of environmental factors from nutrition to housing and crowding are involved. More recently, Kasl and French (1962) have shown that, in one company, status differences between groups account for more than two-thirds of the between group variance in frequency of dispensary visits. Further findings suggest that much of this is mediated through a chain of self-esteem variables.

Anyone who has been through an annual appraisal interview will admit that this is an unsatisfactory social situation. French, Kay, and Meyer (1962) have shown that it usually threatens the self-esteem of the appraisee

TABLE 1

Suspected Sources of Social Maladjustment in Industry and Preliminary CONCEPTUALIZATION OF THE EFfects Involved

\begin{tabular}{l|l}
\hline \multicolumn{1}{c|}{ Source } & \multicolumn{1}{c}{ Conceptualization } \\
\hline 1. Low status & Low self-esteem \\
2. Appraisal interview & Lowered self-esteem \\
3. Job termination & Lowered self-esteem \\
4. Peripheral location in organization & Input overload and/or low social support \\
5. Responsibility & Anxiety \\
6. High rate of technological change & Anxiety and input overload \\
7. Rotating shifts & Depression and family disruption \\
8. Conflict and ambiguity & Input overload \\
9. Poor supervision & Multiple \\
\hline \hline
\end{tabular}


and often lowers the value of the supervisor in the eyes of the supervisee. On the subject of job termination either by reduction in force or by retirement, we have no data of our own; but no one who has read Marie Jahoda's Die Arbeitslosen von Marienthal can escape the negative mental health implications of unemployment.

From a current project (Wolfe and Snoek, 1962), there are data which make it clear that peripheral location in the organization, i.e., the holding of a job in which relationships with multiple groups are required, is a common source of dissatisfaction. The salesman and the public relations officer are the most striking examples of this. Other data from this same study indicate increasing tension and frustration with increasing supervisory responsibility. This is not to say that these dissatisfactions may not be offset by the rewards or that they are necessarily harmful to the individual; however, they are real and form part of the total load which may add up to more than some individuals can tolerate.

From the preliminary analyses of our studies of shift work, it is becoming apparent that shift work, particularly rotation of shifts, results in substantial disruption of family and community life and in a tendency to depression. Current studies will have to be pursued further to make sure that the association of depression with rotating shifts is causal, but it is quite clear that family disruption seldom causes a man to apply for shift work and that rotating each week to a new shift makes a normal family life extremely difficult.

Turning to the sense of conflict and ambiguity that is found to a varying extent in every job, current studies (Wolfe and Snoek, 1962) indicate that tension, i.e., a feeling of being "bothered" by the various aspects of the job, is related to the extent to which the individual in question is being pressured to change his ways. There is no danger that the tension and the pressure might be simply two manifestations of the same phenomenon for the information about tension was obtained from the individual himself while the information about pressure to change was obtained from his superiors, co-workers, and subordinates.

With regard to quality of supervision, comparable data are available on a series of six similar plants. In this series, there is one plant in which the management seems less effective. It is demonstrably less willing to take risks and is less in tune with the perceptions of the employees than that of any other plant in the series. In this plant, the employees are more dissatisfied with their immediate supervisors, with the plant management, and with the company management than are the employees of the other five plants. Incidentally, the men in this plant recently formed a union in order to be sure that their ideas would be listened to by the management.

Illness and social maladjustment. It has been pointed out above that persons located at the periphery of an organization and persons with substantial responsibility show more frequent evidence of social maladjustment than do their fellows. A foreman has both these characteristics; not 


\section{Cobb: Environmental Approach to Mental Health}

TABLE 2

Prevalence of Peptic Ulcers in Foremen and the Craftsmen WHOM THEY SUPERVISE

\begin{tabular}{l|c|c|c}
\hline \multirow{2}{*}{$\begin{array}{c}\text { Certainty of } \\
\text { ulcer Dx. }\end{array}$} & \multicolumn{2}{|c|}{ Prevalence per 100 } & $\begin{array}{c}\text { Approximate ratio } \\
\text { of prevalences }\end{array}$ \\
\cline { 2 - 4 } & Craftsmen & Foremen & 1 \\
Treated & 10 & 12 & 2 \\
X-ray confirmed & 7 & 15 & 10 \\
Gastrectomy & 1 & 12 & 2 \\
Overall & 18 & 38 & \\
\hline No. of men & 272 & 26 & \\
\hline
\end{tabular}

Chi squared $=17.6, \mathrm{p}<0.001$.

only does he have the responsibility to get the work done, but in addition, he has to deal constantly with the conflicts of interest between union and management. Is there any evidence that this group of employees actually have more illness than others? TABLE 2 shows that for peptic ulcer, at least, this is the case. It is, of course, not justified to conclude from the fact that the over-all rate of ulcer disease is twice as high in foreman as in craftsmen that the job contributes to the ulcer; for it might be that susceptibility to ulcers is associated with a characteristic that makes promotion likely. There are two considerations that make it seem probable that the job contributes more to the ulcer than the ulcer does to the promotion. First, the mean pepsinogen level for those not having a gastrectomy is essentially the same for the craftsmen and foremen (Dunn and Cobb, 1962). Second, though the onsets of disease are about equally distributed before and after promotion to foremen, all of the three gastrectomies in foremen were performed after promotion. This suggests that the greater severity of the disease in foremen is in considerable part due to the job. This actually leads one to ask what aspect of the job might contribute to the disease. Clearly, the promotion represents a separation from the worker group and the protection of the union without adequate replacement of social support from the management group that he joins and in which he is likely to remain "low man on the totem pole" for the remainder of his days. Certainly, the notions of lack of protection and lack of social support are consistent with the formulations of the circumstances under which this disease is likely to develop (Kapp et al., 1947; Wiener et. al., 1957; Alexander, 1934; Castelnuovo-Tedesco, 1962). From a theoretical standpoint, the important thing to recognize is that if there is a causal chain here, it is via an interaction of such host factors as pepsinogen level and personality with a specific and relevant environmental situation.

Illness behavior and social maladjustment. TABLE 3 shows a very simple and direct relationship between social maladjustment and illness behavior. These data come from a study done on 314 craftsmen in a plant in the southeastern United States. Here, social maladjustment is estimated by the single question, "Everyone gets a little irritated or annoyed from time to time, 
how much of the time do you find yourself irritated or annoyed?" Of the measures of illness behavior, the number of days lost due to illness is most striking. Here, there is almost a seven-fold difference in number of days lost between those who say they are often irritated and those who reply rarely or never. The differences are in the same direction for the frequency of absences and for the frequency of dispensary visits but are not quite so striking. Statistical tests are not needed to bring out the obvious significance of this association. It is, however, of some interest to add that no such association was found for absence for personal reasons. The first thought that comes to mind on seeing these data is that illness can be a source of irritation, so it is important to recognize that the question about irritation and annoyance was asked at work when the men were presumably in reasonable health and that the absence and dispensary visit data were collected over the two year period preceding the inquiry. It will, of course, be important to see how well this and related questions might predict illness behavior measured subsequent to the collection of the attitudinal data. Other measures of social maladjustment have been studied and their relationship to illness behavior will be reported separately (Kasl and Cobb, 1963). It should be noted that this whole matter is far from simple; for though certain kinds of social maladjustment increase with status in the industrial hierarchy, e.g., that associated with responsibility, others decrease. One suspects that the factors that are most relevant to illness behavior decrease with status, because sick absences decrease with increasing status (Kasl and French, 1962; U. S. Army, 1960; Enterline, 1961). The point that here emerges clearly is that, like "stress," social maladjustment can and should be dissected down to its specific relevant components.

Hysteria, neurosis, and social maladjustment. On turning to this problem, we must admit straight off that this is a difficult field (Kessel, 1962). As yet we have had no measurement experience with it and presumably will not until a psychiatrist joins the group. We have, of course, used various instruments designed to indicate neurotic tendencies; but these are personality characteristics and not ipso facto part of the problem of mental health (Alexander, 1962).

TABle 3

The Relation of the Answers to the Question: “Everyone Gets a Litthe Irrutated on Annoyed from Time to Time, How Much of the Time Do You Find Yourself Irrteated on Annoyed?" and Several. Measures OF ILLNESS BeHAVtoR

\begin{tabular}{l|c|c|c|c}
\hline $\begin{array}{c}\text { Frequency of } \\
\text { irritation }\end{array}$ & $\mathrm{N}$ & $\begin{array}{c}\text { Mean annual } \\
\text { dags lost due } \\
\text { to illness }\end{array}$ & $\begin{array}{c}\text { Mean annual } \\
\text { absences due } \\
\text { to illness }\end{array}$ & $\begin{array}{c}\text { Mean annual } \\
\text { dispensary visits } \\
\text { for illness }\end{array}$ \\
\hline Often & 24 & 20 & 2.2 & 17 \\
Some of the time & 68 & 10 & 1.1 & 14 \\
Occasionally & 162 & 7 & 0.8 & 12 \\
Rarely or never & 60 & 3 & 0.6 & 9 \\
\hline
\end{tabular}


For example, the individual who has acquired a stronger than usual desire or "need" for the orderly completion of tasks may do extremely well in a bank where this characteristic is valued and extremely badly on a farm where everything is always in process and few things are ever finished in any polished sort of a way. In our view, part of the problem of mental health is created by placing square pegs in round holes, and we view one of the main tasks of the industrial psychologist as finding square pegs for square holes; and where this is impossible, rounding the holes a bit or attempting to square the pegs.

Antisocial behavior and social maladjustment. Finally, we come to the area of antisocial behavior. Here we might look at low productivity (Mann, et al., 1963; Likert, 1961; Kahn and Katz, 1960); but for present purposes, we have chosen frequency of communication with coworkers as the behavior of interest. Though it may not be true for all jobs, in managerial jobs reduced communication with coworkers is clearly antisocial behavior; because it reduces the efficiency of the process of management which is wholly dependent on communication for its operation.

TABLE 4

Interaction of Flexibility and LeVel of Conflict on the Frequency of Communication among Executives

\begin{tabular}{l|l|r|r}
\hline \hline $\begin{array}{c}\text { Characteristic } \\
\text { of person }\end{array}$ & $\begin{array}{l}\text { Level of } \\
\text { conflict }\end{array}$ & $\mathrm{N}$ & $\begin{array}{c}\text { Mean frequency } \\
\text { of communication }\end{array}$ \\
\cline { 2 - 4 } Rigid & High & 15 & 3.8 \\
Flexible & High & 14 & 4.2 \\
Flexible & Low & 4 & 5.4 \\
Rigid & Low & 16 & 5.9 \\
\hline \multicolumn{2}{c}{ Overall } & 49 & 4.8 \\
\hline
\end{tabular}

The data come from our studies of role conflict in industrial management. First, 54 focal persons were grouped as high or low on role conflict on the basis of the reports by their associates of changes desired in the focal person with regard to performance, time allocation, personal traits, and style of working with others. Then, they were also grouped as high or low on flexibility by a measure taken from the California Psychological Inventory (Gough, 1956). The results are shown in TABLE 4 which indicate in the first column that there is an association between flexibility and conflict. This is, of course, not so readily seen in this type of presentation. However, when the four-fold table is set up, it can be seen that there is a significant association between flexibility and high conflict. When the means for the index of frequency of communications in the second column are examined, a highly significant difference between the frequency of communications for the rigid, in high and low conflict situations, is revealed. The most obvious conclusion from this table is that one of the characteristics of inflexible people, as defined by the C.P.I. measure, is that they are more than usually communicative in low conflict situations but tend to 
clam up when they feel that they are under a lot of pressure to change. This response pattern is not so striking for the flexible individuals.

Admittedly there is no clear definition of the direction of causality here. In fact, it might be postulated that for inflexible persons, low communication with coworkers leads to conflict and high communication reduces conflict, while for flexible persons no such thing is true. This is, on the face of it, more difficult to accept and seems, therefore, rather less probable than the first explanation. However, only further study, probably involving experimental techniques, will give a final answer to this.

\section{Discussion}

Through all of this presentation has run a theme that there are a variety of readily measurable aspects of the problem of mental health that any research-oriented industrial physician could manage. These include measurement of the prevalence of such psychosomatic diseases as duodenal ulcer, rheumatoid arthritis, and hypertension, and measuring the frequency of dispensary visits and sick absences. These are matters on which every industrial health department has data; the trouble is that the effort required to study these variables for a wide variety of subgroups is usually not expended.

Data on specific mental illnesses and on antisocial behavior are a bit more tricky to collect, largely because of the problem with definitions. However, within-plant comparisons require only adherence to arbitrary criteria to make them useful. It is only when comparisons are to be made between plants, between companies, or even between countries, that sharp and generally agreed upon definitions are required. Any industrial medical department employing a psychiatrist and/or a clinical psychologist has the potential to make a contribution here.

It should be noted that sophisticated hypotheses and analytical techniques are, of course, helpful in bringing out such things as the interaction effect of rigidity and pressure on frequency of communication; but there remain so many simple descriptive things to be done that just taking the effort to look is very worthwhile. Those who are interested in a problem that seems too complex for their previous experience can ask for help from some of those university people who are spending much or all of their time in research in this area.

Finally, the readiness of industry to pitch in and go to work on these problems is attested by the fact that no less than 13 plants belonging to six major corporations have participated in the studies here reported. Furthermore, a part of one of the studies discussed above was done under union auspices when it developed that managements were generally unwilling to back that type of investigation. Suffice it to say that forwardlooking companies can always get together with forward-looking unions when the subject is health. It is the earnest wish of the research workers in this field that all parties might be as forward-looking as some of our corporations and unions. 


\section{Cobb: Environmental Approach to Mental Health}

\section{Conclusions}

1. It is clear that for sound studies in mental health, it is necessary to study not just personality or environment but also their interaction. To this end, an increase in emphasis on environmental factors is urged.

2. Since positive mental health is at least as difficult to define as positive physical health, it is suggested that for the time being most studies be directed at the problem of mental health which is composed of those parts of illness, illness behavior, hysteria, neurosis, etc., and antisocial behavior which are derived from social maladjustment.

3 . Some areas of the industrial organization with high rates for social maladjustment have been identified and some kinds of relationships between social maladjustment and the components of the problem of mental health have been illustrated.

4. In each of these areas with the possible exception of hysteria, neurosis, etc., specific measurable variables are available for study.

\section{Acknowledgments}

The work here reported has had the support and backing of the following organizations: National Institutes of Health, Bethesda, Maryland, A-308, A-6017, M-3276, M-3346, M-3874, 3M-9132, 3M-9177; Chrysler Corp., Detroit, Mich.; Detroit Edison Co., Detroit, Mich.; General Electric Co., New York, N. Y.; Michigan Bell Telephone Co., Detroit, Mich.; Standard Oil of New Jersey, New York, N. Y.; United Textile Workers of America, New York, N. Y.; and Union Carbide Co., New York, N. Y.

\section{References}

Alexander, F. 1934. The influence of psychologic factors upon gastrointestinal disturbances. Psychoanal. Quart. 3: 501-539.

Alexander, F. 1962. The development of psychosomatic medicine. Psychosom. Med. 24: 13-24.

Castelnuovo-Tenesco, P. 1962. Emotional antecedents of perforation of ulcers of the stomach and duodenum. Psychosom. Med. 24: 398-416.

Committee for the Special Research Project in the Health Insurance Plan of Greater New York. 1957. Health and Medical Care in New York City. Harvard Univ. Press. Cambridge, Mass.

Dalton, K. 1960a. Effect of menstruation on schoolgirls' weekly work. Brit. Med. J. 1: 326-328.

Dalton, K. 1960b. Menstruation and accidents. Brit. Med. J. 2: 1425-1426.

DALton, K. 1960c. Schoolgirls' behavior and menstruation. Brit. Med. J. 2: 16471649.

Dalton, K. 1961. Menstruation and crime. Brit. Med. J. 2: 1752-1753.

Dunn, J. P. \& S. Coвb. 1962. Frequency of peptic ulcer among executives, craftsmen, and foremen. J. Occup. Med. 4: 343-348.

Enterline, P. E. 1961. Work loss due to illness in selected occupations and industries. J. Occup. Med. 3: 405-411.

Forster, F. M. 1955. The epilepsies and convulsive disorders. In Clinical Neurology. : 1036-1074. A. B. Baker, Ed. Hoeber. New York, N. Y. 
French, J. R. P., Jr., E. Kay \& H. H. Meyer. 1962. A study of threat and participation in an industrial performance appraisal program. Behavioral Research Service. Management Development and Employee Relations Services. General Electric Co. New York, N. Y.

French, J. R. P., JR. \& R. L. Kahn. 1962. A programmatic approach to studying the industrial environment and mental health. J. Soc. Issues. 18 (3): $1-47$.

Govgr, H. G. 1956. The California Psychological Inventory. Consulting Psychologists' Press. Palo Alto, Calif.

Great Britain, Registrar General. 1958. Decennial supplement, England \& Wales. 1951. Occupational Mortality. H.M.S.O. London, England.

JahodA, M. 1933. Die Arbeitslosen von Marienthal. S. Hirzel. Leipzig, Germany.

KAHN, R. L. \& D. KATZ. 1960. Leadership practices in relation to productivity and morale. In Group Dynamics. 2nd ed.: 554-570. D. Cartwright \& A. Zander, Ed. Row, Peterson and Co. Evanston, Ill.

Kapp, F. T., M. Rosenbaum \& J. Romano. 1947. Psychological factors in men with peptic ulcers. Am. J. Psychiat. 103: 700-704.

KasL, S. V. \& S. CoBB. 1963. Manuscript in preparation.

KASL, S. V. \& J. R. P. French, JR. 1962. The effects of occupational status on physical and mental health. J. Soc. Issues. 18(3): 67-89.

Kessed, N. 1962. Neurosis and the N. H. S. Twentieth Cent. 172(1015): 55-65.

Likert, R. 1961. New Patterns of Management. McGraw-Hill. New York, N. Y.

ManN, F. C., B. INdIK \& V. H. VRoom. 1963. Manuscript in preparation.

Metropolitan Life Insurance Co. 1960. Recent and future mortality trends. Statist. Bull. $41(6): 1-3$.

SHERwOOD, J. J. 1962. Self-identity and self-actualization-a theory and research. Unpublished Ph.D. dissertation. The Univ. of Mich. Ann Arbor, Mich.

Szasz, T. S. 1961. The Myth of Mental Illness: Foundations of a Theory of Personal Conduct. Hoeber. New York, N. Y.

U. S. Department of the Army, Office of the Deputy Chief of Staff for Personnel. 1960. Sick leave study. Army Progress Report TP-3. Part 3: 1-3.

Weiner, H., M. Thaler, M. F. Reiser \& I. A. Mirsky. 1957. Etiology of duodenal ulcer. Psychosom. Med, 19: 1-10.

Wolfe, D. M. \& J. D. SNoex. 1962. A study of tensions and adjustment under role conflict. J. Soc. Issues. 18(3): 102-121.

World Health Organization. 1960. Epidemiology of Mental Disorders. Tech. Rept. Ser. 185. W.H.O. Geneva, Switzerland. 